\title{
Magnetic Phase Diagram of Nanostructured Zinc Ferrite as a Function of Inversion Degree $\delta$
}

M A Cobos $^{a, b}$, P de la Presa ${ }^{a, c}$, I. Llorente ${ }^{b}, J M$ Alonso $^{a, d}$, A García-Escorial ${ }^{b}, P$ Marin $^{a, c}$, A. Hernando ${ }^{a, c, e}, J$ A Jiménez ${ }^{b}$.

a. Instituto de Magnetismo aplicado (UCM-ADIF-CSIC), A6 22,500 Km, 28260 Las Rozas, Spain

b. Centro Nacional de Investigaciones Metalúrgicas (CENIM-CSIC), Avda. Gregorio del Amo, 8, 28040 Madrid, Spain

c. Dpto Física de Materiales, UCM, Ciudad Universitaria, 28040 Madrid, Spain

d. Instituto de Ciencias de Materiales de Madrid (ICMM-CSIC), Avda Sor Juana Inés de la Cruz 8, 28040 Madrid, Spain

e. Donostia International Physics Center DIPC, Paseo Manuel de Lardizabal 4, 2018, Donostia-San Sebastián, Spain 
Table S1: Structural parameters of the zinc ferrites for low and high inversion degree.

\begin{tabular}{|c|c|c|}
\hline & \multicolumn{2}{|c|}{ Inversion degree $\delta$} \\
\hline & $\delta=0.18$ & $\delta=0.58$ \\
\hline \multicolumn{3}{|c|}{ Atomic positions } \\
\hline A Site (Fe/Zn) & $(0.375 .0 .375,0.375)$ & $(0.375 .0 .375,0.375)$ \\
\hline B Site (Fe/Zn) & $(0,0,0)$ & $(0,0,0)$ \\
\hline O Site & $(0.243,0.243,0.243)$ & $(0.246,0.246,0.246)$ \\
\hline \multicolumn{3}{|c|}{ Interatomic distances (Angstrom) } \\
\hline$A B$ & $3.497(1)$ & $3.496(1)$ \\
\hline BB & $2.982(1)$ & $2.981(1)$ \\
\hline AA & $3.652(1)$ & $3.651(1)$ \\
\hline $\mathrm{AO}$ & $1.928(1)$ & $1.884(1)$ \\
\hline $\mathrm{BO}$ & $2.051(1)$ & $2.075(1)$ \\
\hline \multicolumn{3}{|c|}{ Angles (degrees) } \\
\hline$A O B$ & $122.93(1)$ & $123.95(1)$ \\
\hline $\mathrm{BOB}$ & $93.25(1)$ & $91.84(1)$ \\
\hline
\end{tabular}

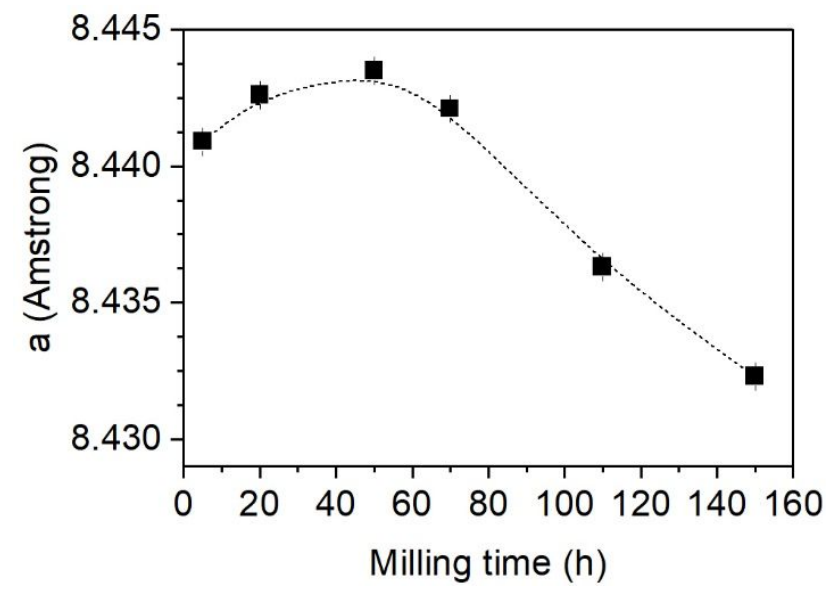

Figure S1: Cell parameter $a$ as a function of the milling time 


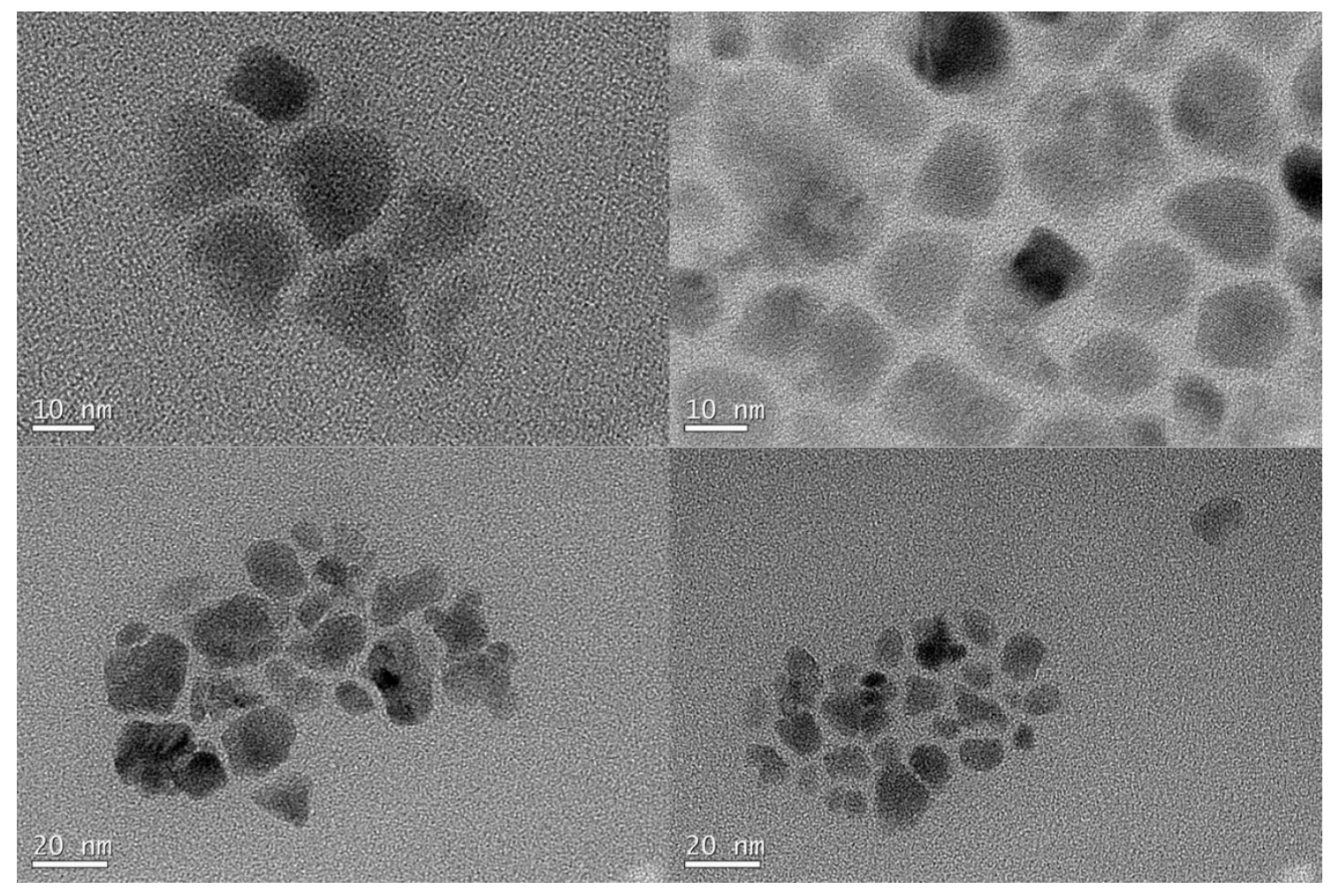

Figure S2: TEM images of as-milled zinc ferrites samples. 